\title{
PARTICIPAÇÃO NOS LUCROS OU RESULTADOS E GESTÃO DA SUBJETIVIDADE
}

\section{Fábio de Almeida Rego Campinho}

Mestrando em Direito pela Universidade Federal do Paraná.

e-mail: fabiocampinho@yahoo.com.br

RESUMO: A regulação infra-constitucional da PLR, a partir da Medida Provisória no 794 de 1994, com sua conversão na Lei 10.101 de 2000, não pode ser compreendida sem uma análise do contexto em que se deu sua aplicação, ou seja, a difusão do ideário neoliberal e a reestruturação produtiva das indústrias brasileiras. Optou-se por enfatizar este último elemento e traçar as relações entre a PLR e as novas formas de gestão da subjetividade no ambiente de trabalho, discutindo-se como este instrumento jurídico se relaciona com a implementação dos Círculos de Qualidade Total (CQTs), do trabalho em equipe, da polivalência e de um discurso empresarial pautado nas noções de parceria e de integração entre os interesses do capital e do trabalho.

PALAVRAS-CHAVE: Participação nos lucros ou resultados; Trabalho; Reestruturação produtiva; Subjetividade. 


\section{O CONTEXTO DE REGULAÇÃO DA PARTICIPAÇÃO NOS LUCROS OU RESULTADOS NO BRASIL}

A participação nos lucros não é um fenômeno recente. Em 1812 um decreto napoleônico a estabelecera para os membros da Comedie Française e em 1917 fora positivada pela constituição do México. No início do século XX, em vários países europeus - Inglaterra, França, Alemanha, Estados Unidos, Bélgica, Itália, Holanda, Rússia e Suécia - algumas empresas a introduziram voluntariamente ${ }^{1}$.

A inclusão da participação nos lucros no ordenamento jurídico brasileiro ocorreu com a Constituição de 1946 (art. 157, IV), tendo sido prevista posteriomente pela Carta de 1967 (art. 165, V, conforme Emenda Constitucional o 1 de 1969). A Constituição de 1988 (art. 7º, $\mathrm{XI}$ ) também disciplinou a matéria, tendo inovado ao acrescentar referência à participação nos resultados ${ }^{2}$.

Apesar da presença remota no ordenamento pátrio, sua efetivação como direito nunca havia ocorrido, seja por falta de regulação infraconstitucional (Constituições de 1946 e 1988), seja por um desvirtuamento em sua disciplina (Constituição de 1967). Neste último caso a efetivação do direito constitucional deuse através da criação do sistema PIS-PASEP (Leis Complementares o 7 e 8 de 1970), que representava "muito mais a participação do trabalhador em diluído percentual da renda nacional do que propriamente sua participação nos lucros das empresas"3.

Porém, na década de noventa do século passado, devido a uma série de fatores políticos e sócio-econômicos, a regulamentação da PLR (Participação nos lucros ou resultados) surgiu na pauta de prioridades do governo Fernando Henrique Cardoso, vigendo, a partir de 1994, através de uma medida provisória reiteradamente editada que em 2000 finalmente foi convertida na Lei oㅜ 10.101. Sua implementação deu-se em um contexto marcado pelo avanço do ideário neoliberal

${ }^{1}$ SUSSEKIND, A. Curso de Direito do Trabalho. Rio de Janeiro: Renovar: 2002. p. 435.

${ }^{2}$ Art. 7ํ. São direitos dos trabalhadores urbanos e rurais: XI - participação nos lucros, ou resultados, desvinculada da remuneração, e, excepcionalmente, participação na gestão da empresa, conforme definido em lei.

${ }^{3}$ MALLET, E. Participação nos lucros. DALLEGRAVE NETO, J. A. Direito do trabalho: estudos. São Paulo: LTr, 1997. p. 150. "Com a constituição de 1988 afastou-se definitivamente qualquer ligação PIS-PASEP com a participação em lucros" (ibidem, p. 151) 
na vida política brasileira e está inserida no conjunto de práticas de flexibilização das relações trabalhistas gestadas neste período ${ }^{4}$.

A abertura econômica promovida pelo Plano Real tornava necessário expedientes capazes de garantir a competitividade das empresas brasileiras. A PLR, desta forma, torna-se funcional, pois possibilita uma melhor adequação dos gastos com pessoal ao desempenho da empresa, um maior engajamento dos trabalhadores no sentido de contribuir para com o aumento de produtividade, bem como uma redução de custos fixos à medida que a participação é desvinculada da remuneração ${ }^{5}$. Além disso, deve-se atentar para o fato de que a medida provisória que estabeleceu o plano de estabilização econômica (MP $\mathrm{n}$ ํ.1.053/94) proibiu todas as cláusulas de reajuste de salários baseadas em índices oficiais de preços e eliminou as políticas estatais de reajuste salarial ${ }^{6}$.

Neste novo contexto, marcado pelo fim das políticas salariais, a estratégia de atuação sindical fundada na "uniformização dos padrões de reajuste por meio de negociação coletiva ou até mesmo de sentenças normativas"7 restou frustrada, dificilmente resultando em recomposição salarial real ${ }^{8}$. A PLR representou um refúgio, ou seja, a possibilidade de um acréscimo não vinculado a remuneração e capaz de aliviar a ausência de indexação. Porém, contribuiu para uma significativa mudança nas estratégias de atuação sindical, com um progressivo aumento dos acordos coletivos por empresa em detrimento das convenções e dos acordos

4 "Especialmente durante o Plano Real, tornam-se evidentes os indícios de um aprofundamento da desregulação das normas do trabalho e uma flexibilização das relações de trabalho no Brasil, o que se expressa tanto pelas mudanças institucionais como pela dinâmica dos atores sociais em um contexto marcado pela desregulação comercial e financeira, pelas inovações tecnológicas e organizacionais, pelo medíocre e instável desempenho da economia, pela crescente elevação do desemprego e pelo crescimento da precarização do trabalho" (KREIN, J. D. A reforma trabalhista de FHC: efetividade e conseqüências. Revista Trabalhista. Rio de Janeiro, v. 2, p. 135-164, abr./jun. 2002, p.135.

5 Os efeitos desta desvinculação são que estes valores "não podem ser computados: a) para complementar o salário devido ao empregado, b) na base de incidência dos depósitos do FGTS, das contribuições previdenciárias e de outros tributos cujo fato gerador seja a remuneração do empregado; c) no cálculo de adicionais, indenizações e outras prestações que incidem sobre a remuneração ou salário" (SUSSEKIND, A. op. cit., p. 437)

${ }^{6}$ art. 10, MP no 1.053/95 (convertida na Lei 10.192/2001): Os salários e demais condições referentes ao trabalho continuam a ser fixados e revistos, na respectiva data-base anual, por intermédio de livre negociação coletiva.

7 OLIVEIRA, M. A. Tendências recentes das negociações coletivas no Brasil. In: ENCONTRO ANUAL DA ANPOCS, XXV, 2001, Caxambú.

${ }^{8}$ O crescimento dos acordos de PLR, a partir de 1995, coincide com o plano de estabilização de preços. A partir de então, há uma queda progressiva no número de categorias que asseguraram a recomposição do poder aquisitivo dos salários (KREIN, op. cit., p. 151) 
envolvendo duas ou mais empresas. Há, a partir da implementação da PLR, uma verdadeira fragmentação das lutas sindicais, com a descentralização das negociações e com o foco de atuação voltando-se para o interior da empresas, pois a própria natureza dos temas negociados (produtividade, qualidade, metas, resultados etc.) acaba por dificultar uma pauta homogênea que envolva toda a categoria.

Tal tendência descentralizadora parece ter sido impulsionada pela própria regulação infraconstitucional da PLR, ou seja, a Lei 10.101 de 2000 procurou regê-la de maneira mínima e aberta, sem ser exaustiva na disciplina das formas de participação. Prevaleceu o princípio de que só "o conhecimento da realidade concreta, peculiar a cada empresa e variável no tempo, permite a adoção de critérios aptos a reger o instituto"9. Portanto, embora sejam fixados parâmetros que devem constar nas negociações (art 2º, l - índices de produtividade, qualidade ou lucratividade da empresa; II - programas de metas, resultados e prazos, pactuados previamente), tais critérios, conforme a própria lei prevê, são meramente exemplificativos $^{10}$.

Diante desta situação de regulação mínima e de incentivo a composição autônoma dos atores envolvidos, as modalidades possíveis de participação multiplicaram-se. TUMA, analisando diversos acordos e convenções coletivas, enumerou quatro tipos principais, embora a partir dos mesmos possam existir desdobramentos diferenciados conforme o caso concreto. São eles: a participação nos lucros, a participação nos resultados, a participação nos lucros e resultados e a participação independente ${ }^{11}$.

${ }^{9}$ ROMITA, A. S. A participação nos lucros a luz das medidas provisórias. Trabalho \& Processo. São Paulo, v. 6, p. 6-19, set. 1995. p. 9

${ }^{10}$ Tal conclusão advém da expressão "entre outros" presente no art. ㄴo da Lei 10. 101.

${ }^{11}$ TUMA, F. Participação dos trabalhadores nos lucros ou resultados das empresas: incentivo à eficiência ou substituição dos salários. São Paulo, LTr, 1999. A categoria participação independente tem validade analítica para a economia e não para o direito. A Lei 10.101 que trata da PLR não prevê o ajustamento de parcelas que não tenham relação alguma com o lucro ou metas. É até possível a pactuação dessas parcelas, mas elas terão natureza remuneratória, já que não cumprem os requisitos legais da PLR. 


\section{TAYLORISMO/FORDISMO, OPERÁRIO-MASSA E DIREITO DO TRABALHO}

Conforme descrito acima a PLR é regulamentada no Brasil justamente em um momento marcado pela difusão do neoliberalismo, porém, para compreender seu impulso não basta a percepção desta dimensão, é preciso, ainda que brevemente, esboçar as profundas modificações ocorridas na esfera da organização da produção, processo denominado reestruturação produtiva ${ }^{12}$, que trouxe amplas repercussões na forma de ser de classe trabalhadora a partir de então, bem como, nas formas de regulação jurídica das relações de trabalho.

Tais transformações estão ligadas ao esgotamento do padrão produtivo hegemônico em grande parte do século XX (taylorismo/fordismo), que teve sua fase de apogeu principalmente nos chamados anos de ouro do pós-guerra, período em que grande parte dos países da Europa Ocidental conseguiram um alto grau de crescimento econômico associado a uma certa equidade na distribuição de dividendos entre capital e trabalho. Tal conformação societal é descrita por alguns autores como "compromisso fordista"13, ou ainda, "compromisso social-democrata"14 e, embora tivesse efeitos amplos sobre diversas esferas sociais (Estado, mercado, cultura, sexualidade, etc.) teve como alicerce a grande fábrica fordista. É, portanto, partindo dessa forma organizacional que pode-se posteriormente compreender sua posterior crise e reestruturação.

Em uma primeira aproximação da organização fordista, pode-se defini-la como a adaptação do sistema taylorista de administração científica para um linha de montagem. Taylor possui uma brilhante e cínica frase que compara o trabalhador a um "gorila amestrado". É justamente esse o perfil de trabalhador que o seu método procura construir. Ele considerava que grande parte das empresas estadunidenses do final do século XIX eram improdutivas e as razões para isso estavam em um sistema que privilegiava a indolência dos trabalhadores. Em cada empresa existiam diversos trabalhadores que desempenhavam tarefas idênticas utilizando-se de

\footnotetext{
12 Ambos, o avanço do neoliberalismo e a reestruturação produtiva fazem parte de um mesmo contexto e estão profundamente articulados, surgiram como resposta integrada do capital à crise de acumulação que se abateu sobre o Welfare State a partir da década de 1970. Apesar disso, ambos o fenômenos possuem certas especificidades, o que requer uma análise própria.

13 vide NEGRI, Antônio. Constituent Republic. In: VIRNO, Paolo; HARDT, Michael, Radical thought in Italy. Minneapolis: University of Minnessota Press, 1996, p. 213-220.
} 
procedimentos diferentes, conforme o savoir-faire de cada um. Disto resultava um enorme desperdício de movimentos, já que nem sempre a forma mais produtiva (one best way) era aquela efetivamente empregada por todos. Porém, a administração ficava de mão atadas diante dessa situação, já que não possuía mecanismos seguros para aferir a produtividade ideal, ou seja, por não dispor dos conhecimentos detalhados sobre o saber-fazer operário, a gerência acabaria por submeter-se às informações emitidas pelo sindicato, o que aumentava o poder deste último.

A solução para tais problemas estaria no estudo do trabalho operário realizado pela gerência científica. O cronômetro esquadrinharia o tempo de cada pequeno movimento dos trabalhadores de forma que ao final se pudesse deduzir a forma de trabalho mais econômica e produtiva, que, a partir de então, seria imposta à todos os trabalhadores que realizassem uma determinada tarefa. Trata-se, portanto, não de um grande avanço na maquinaria, mas sim da própria construção do homem-máquina. Não da objetivação do trabalho vivo que se converte em máquina, mas da objetivação da própria subjetividade, que se torna dócil através da "elaboração temporal do ato" e da supressão de suas especialidades profissionais. $O$ antigo operário de ofício é expropriado, seu saber é agora controlado pela gerência científica, sua existência passa a ser uma existência maquinal ${ }^{15}$.

O que Ford fez em sua indústria de automóveis foi associar a fracionamento de tarefas típicos do taylorismo com uma esteira rolante por onde os componentes dos seus carros modelos $\mathrm{T}$ deveriam movimentar-se, ligando assim todos os trabalhos individuais sucessivos. Mas o empreendimento de Ford não se resume a isso. Para otimizar a produção foi preciso padronizar os componentes, o que só pode ser feito àquela época com a integração dos diversos elos da cadeia produtiva em um mesmo espaço fabril, fenômeno denominado integração vertical. Além disso, deve-se ressaltar que o salto de produtividade proporcionado pela nova forma de trabalho socialmente combinado, possuía entre as suas características a homogeneidade dos produtos (no caso específico de Ford o modelo T) e requisitava um grandioso esforço para a construção de um novo leque de consumidores, consubstanciado na noção de "consumo de massas".

14 BIHR, Alain. Da grande noite à alternativa: o movimento operário europeu em crise. 2. ed. São Paulo: Boitempo, 1998, p. 35-50 
Dessa forma de ser da produção, constitui-se também uma forma específica de subjetividade operária, que não deixa de ser extremamente contraditória. Pois, se esse grande "aparelho de seqüestro" fabril encarcera ao concentrar multidões de trabalhadores; se individualiza os corpos evitando os contatos aleatórios, fixando cada qual de forma intensa ao seu posto e à sua operação parcial; se destrói os antigos laços profissionais baseados na especialidade substituindo-os por um verdadeiro homem-máquina, reprodutor de movimentos uniformes; por outro lado, "a massificação lança assim as bases de uma nova identidade, de uma subjetividade mais radical, baseada na recusa da expropriação generalizada, pelo fordismo, em relação ao domínio de suas condições de existência"16. Além disso, se é certo que há uma divisão milimétrica do tempo ( $\mathrm{Na}$ General Motors, por exemplo, o trabalhador era "pago pelo número de décimos de hora que trabalhasse"17), por outro lado, "o tempo rotinizado se tornara uma arena onde os trabalhadores podiam afirmar suas próprias exigências, uma arena que dava poder"18. Essa contradição vêm expressa de forma ainda nítida por DELEUZE, quando diz que "a fábrica constituía os indivíduos em um só corpo, para a dupla vantagem do patronato que vigiava cada elemento da massa, e dos sindicatos que mobilizavam um massa de resistência"19.

Esta forma de subjetividade operária descrita acima, que Negri denomina operário-massa, é o resultado e ao mesmo tempo a impulsionadora de toda uma forma de regulação do trabalho e da seguridade social, que está no âmago do "compromisso social-democrata", e que posteriormente ela própria contribuirá para destruir. A disputa em torno do controle do tempo travada pelos sindicatos e partidos operários expressa-se através da redução de jornada, da regulamentação extenuante dos intervalos inter e intra jornada e da fixação de seus limites externos (por exemplo, na discussão sobre a natureza do período de transporte até o local de trabalho); mas o tempo extrapola os limites da fábrica passando a organizar o próprio tempo de vida, por exemplo, nos casos dos sistemas de previdência social.

\footnotetext{
${ }^{15}$ Ver TAYLOR, Frederick Winslow. Princípios da administração científica. 8. ed. São Paulo: Atlas, 1990.

${ }^{16}$ BIHR, Alain. Da grande noite à alternativa: o movimento operário europeu em crise. 2. ed. São Paulo: Boitempo, 1998, p. 57.

${ }^{17}$ SENNET, Richard. A corrosão do caráter. 6. ed. São Paulo: Ed. Record, 2002, p. 47.

18 SENNET, op. cit., p. 48.

${ }^{19}$ DELEUZE, Gilles. Conversações. trad. Peter Pál Pelbart. Rio de janeiro: Ed. 34, 1998, p. 221.
} 
Além disso, fixam-se cada vez mais proteções ao salário, seja através da irredutibilidade, das diversas formas de equiparação salarial e da integração de diversas parcelas à remuneração. Esta torna-se cada vez mais rígida, seja pela forma de sua fixação, que já não envolve apenas os contraentes diretos, mas ou o Estado ou as diversas formas de normatização coletiva; ou ainda, pela relativa estabilidade dos trabalhadores (com a predominância dos contratos a prazo indeterminado) e pela rigidez da jornada (mesmo a jornada extraordinária é uma exceção que só confirma a regra ${ }^{20}$ ). Além disso, a própria forma de vigilância e disciplina que caracteriza a organização fordista passa a ser a base para a determinação relação de trabalho subordinado, o que significa dizer, de acordo com MACHADO que:

O direito do trabalho, para fixar a noção de subordinação jurídica, absorveu principalmente $o$ critério subjetivo de sujeição ao controle e à fiscalização direta, à moda taylorista. O controle disciplinar do trabalho, legitimado pelo direito do trabalho, mesmo operando fora da contratualidade, é o exemplo mais emblemático, pois atua justamente para garantir a disciplina, combatendo a desídia, a indisciplina e a insubordinação no trabalho ${ }^{21}$

\section{TOYOTISMO, OPERÁRIO FRAGMENTADO E DIREITO DO TRABALHO}

O fordismo, as formas de subjetividade por ele engendradas e a regulação institucional que esse modelo consolida entram em crise a partir da década de 1970. A compreensão deste processo é por demais complexa, mas é preciso abordá-lo ainda que brevemente. A premissa de que se parte neste ensaio é a de que a crise do fordismo é a manifestação da crise do padrão de acumulação capitalista e que as mudanças subsequentes na esfera da produção são uma forma de reação do capital ao obstáculos provocados por tal situação.

A organização do trabalho social fordista chega, na década de 1970, à uma série de impasses, sendo que entre eles pode-se atentar para elementos objetivos e subjetivos, o que certamente não implica em uma separação completa entre ambas as esferas. Descrever este quadro de forma pormenorizada extrapola as possibilidades deste ensaio, mas cabe aqui a sucinta abordagem de alguns aspectos. O primeiro deles é a dificuldade de manutenção da ascensão da produtividade à medida em que o fordismo se espraia pelos

${ }^{20}$ Sobre a "função-garantia da estandardização do tempo de trabalho" vide OFFE, Claus. Trabalho e Sociedade. v. 1. Rio de Janeiro: Tempo Social, 1989. p. 195-215. 
diversos setores produtivos, ou seja: se em um primeiro momento o salto produtivo baseava-se na expansão do fordismo, a partir da década de 1970 isso já não é mais possível. Resta, portanto, a possibilidade de aprofundamento da disciplina fordista, o que a partir de certo ponto passa a ser contraproducente. O fracionamento científico dos movimentos propugnado por Taylor, se levado ao extremo torna-se disfuncional; a ordem prescritiva emanada da gerência não pode prescindir por completo da criatividade operária sob pena de se inviabilizar. Além disso, a intensificação dos métodos se confrontava cada vez mais com o operariado. Um segundo aspecto relevante consiste nas limitações da própria norma de consumo fordista, baseada no "consumo de massas". A homogeneidade dos bens duráveis produzidos tinha perspectivas de expansão até o ponto em que grande parte dos operários estivessem incluídos neste tipo de consumo, porém, posteriormente, era inevitável uma redução dos coeficientes de consumo, o que demandava uma estrutura produtiva mais adaptada à situação de crescimento lento, ou até mesmo de estagnação econômica. Neste perspetiva, tornava-se necessário que as empresas fossem capazes de captar e construir nichos cada vez mais especializados de mercado, pautados em preferências específicas e individualizadas e, além disso, dotar-se de uma forma organizativa mais flexível capaz de modificar-se em tempo mínimo conectando-se quase que instantaneamente a quaisquer variações de demanda. Por último, deve-se atentar para a chamada "revolta do operário massa". Se nos primeiros anos do fordismo uma certa elevação de salários (por exemplo, a diária de 8 dólares de Ford) e a inserção na sociedade de consumo, com todas as experiências individualizantes que ela proporciona, compensavam o trabalho fabril estafante e desprovido de sentido, a situação muda nas gerações subsequentes. A juventude estudantil e os novos trabalhadores estão pouco dispostos a "perder a vida para ganhá-la". Tal situação resulta em uma série de resistências que vão desde a recusa do trabalho, expressa em elevados índices de absenteísmo e de turn over, até a luta pela "reconquista de um poder sobre o processo de trabalho"22, redundando em ocupações de fábricas, greves, propostas de auto-gestão, etc. Todos esses fatores ameaçavam a produtividade e acumulação do capital, sendo necessário uma reestruturação que desse conta destes diversos desafios.

O modelo paradigmático da nova forma de gestão da produção e do trabalho é o japonês, melhor denominado de toyotismo ${ }^{23}$, e que vai difundir-se pelo ocidente a partir da década de 1970, ainda que com diversas adaptações. Sua lógica é, em certo sentido, inversa a da produção em massa fordista e foi concebida com base

21 MACHADO, Sidney. A subordinação jurídica na relação de trabalho: uma perspectiva reconstrutiva. Tese de Doutoramento. Disponível na Biblioteca do Setor de Ciência Jurídicas da UFPR. p. 73.

22 BIHR, op. cit., p. 61. 
nos modelos dos supermercados estadunidenses. Trata-se de uma espécie de produção puxada pela demanda em que a atividade da linha está diretamente conectada aos índices de venda, de modo que as alterações quantitativas ou qualitativas nas mesmas repercutem diretamente na organização da produção, tudo isso acionado pelo sistema do just in time. Os grandes estoques do antigo modelo são abolidos, a palavra de ordem é o estoque mínimo, bem como, a redução de custos através da luta constante contra o desperdício. O gigantesco aparelho de disciplinar (grande fábrica fordista) é substituído por uma cadeia integrada de fornecedores interligados por sistemas de informática. As necessidades de componentes da empresa central são cada vez mais externalizadas, de modo que ela mantenha somente as atividades julgadas vitais, fragmentando-se também a alocação dos trabalhadores.

Neste contexto, a rigidez do "gorila amestrado" de Taylor não tem mais vez, ela é inerte demais para as novas necessidades produtivas. A palavra do momento é flexibilidade. Dentre os diversos sentidos que se podem atribuir a este vocábulo "mágico" estão: a constante possibilidade de adaptação às novas circunstâncias, a maleabilidade, a capacidade de desempenhar diversas funções, a recusa aos padrões burocráticos pré-estabelecidos, que constituem óbices à criatividade e à inovação, a destruição criativa, ou seja, a possibilidade de destruição de modelos antiquados e de elaboração de novos paradigmas em um tempo mínimo. Não só as máquinas precisam ser adaptáveis as recorrentes variações da demanda, mas o próprios homens que as manejam devem ser capazes de adequar-se à inovação contínua.

A vigilância hierárquica típica do panóptico foucaultiano já não é o meio mais eficaz. Ela cria um ambiente autoritário pouco propenso à criatividade e, ainda que não desempenhe um papel unicamente repressivo, só é capaz de construir movimentos orquestrados, mas nunca pode dar lugar a originalidade. Já com o

${ }^{23}$ Sobre toyotismo ver: GOUNET, Thomas. Fordismo e toyotismo na civilização do automóvel. São Paulo: Boitempo, 2002 e CORIAT, Benjamin. Pensar pelo avesso: o modelo japonês de trabalho e organização. Rio de Janeiro: Revan, 1994. 
controle $^{24}$, forma mais fluída da gestão dos corpos, a articulação das diversas inteligências individuais passa a ser também um recurso produtivo e, para que possa desabrochar, é preciso que haja meios de cooperação. A participação passa a ser valorizada. Formam-se os CQT (Círculos de Qualidade Total), organizados através de equipes de "colaboradores" que propõem formas de solucionar problemas, elaboram metas de qualidade e avaliam o cumprimento ou não das mesmas.

Com tais mudanças surgem diversas fissuras no próprio Direito do Trabalho. Entre elas pode-se apontar: 1. Uma certa perda dos referenciais para a definição do conceito de subordinação, já que o mesmo está profundamente ligado às formas de vigilância e direção do trabalho típica do modelo fordista e que não comportam essa ampliação da esfera de autonomia presente nos times de trabalho. 2. A perda do referencial rígido da jornada de trabalho e da remuneração com a flexibilização de ambos, no primeiro caso através das diversas formas de jornada variável (no caso brasileiro a compensação de jornada) e no segundo através das remuneração por metas, prêmios e participação nos lucros ou resultados.

\section{PLR E REESTRUTURAÇÃo PRODUTIVA}

Como abordado acima, o modelo paradigmático da reestruturação produtiva foi o toyotismo, porém, é preciso evitar alguns equívocos e generalizações. A difusão deste modelo para o Ocidente não se deu sem uma série de adaptações relativas as particularidades culturais e econômicas de cada país. Além disso, deve-se ressaltar que embora alguns autores mais entusiastas tenham visto na difusão do modelo japonês um verdadeira superação do fordismo, diversos estudos empíricos vêm apontando a existência de modelos híbridos, em que interagem, por exemplo, um

${ }^{24}$ Deleuze, em seu Post-scriptum sobre a sociedades de controle, alertava, seguindo as intuições de Foucault, que "sociedades disciplinares é o que já não éramos mais, o que deixávamos de ser" (DELEUZE, Gilles. Conversações. trad. Peter Pál Pelbart. Rio de janeiro: Ed. 34, 1998, p. 220). Viver-se-ia atualmente a transição para uma nova forma de sociedade que para aquele autor se denominaria sociedade de controle. Nela os muros dos antigos aparelhos de seqüestro simplesmente ruíram e o controle parece se espraiar para os diversos âmbitos da vida. A geografia do controle difundiu-se para além das escolas, dos hospitais, das prisões e das fábricas. Os antigos moldes transformaram-se em modulações muito mais variáveis e, por isso, as tradicionais instituições estão crise. A antiga fábrica, com seu grande parque produtivo, que concentrava dentro de seu espaço um enorme contingente de homens e máquinas tornou-se agora empresa descentralizada. $O$ corpo único de resistência articulado em torno do sindicato, fragmentou-se. Tornou-se terceirizado, precarizado, autônomo, trabalhador em domicílio, etc. O hospital e as instituições psiquiátricas são cada vez mais questionados. Surgem os chamados hospitais-dia e os médicos da família. O mesmo refluxo se dá com as prisões e com a escola, sendo as penas alternativas e o ensino à distância alguns dos exemplos desse processo. A tecnologia do panóptico e seu olhar fixo tornam-se quase arcaicos frente às novas técnicas informacionais (ibidem, p.219-226). 
novo discurso pautado na flexibilidade, polivalência e trabalho em equipe com antigas formas de linha de montagem, ainda que com algumas adaptações ${ }^{25}$.

Porém, a questão que persiste mal resolvida pela argumentação aqui esboçada diz respeito as relações entre a Participação nos Lucros ou Resultados e reestruturação produtiva. Quais são os pontos de confluência desses fenômenos? Como se dá a interseção entre os mesmos e como se influenciam mutuamente? Para responder a tais indagações pretende-se enfocar especialmente um dentre os três aspectos relacionados no item 4 que teriam impulsionado a regulação infraconstitucional da PLR: o envolvimento do trabalhador no sentido de comprometer-se com o aumento da produtividade da empresa ${ }^{26}$. Neste caso, a PLR transforma-se em verdadeiro instrumento gerencial, pois, diferencia desempenhos individuais e dos grupos de trabalho e os põe uns contra os outros em eterna competição; organiza o trabalho de forma a não só extrair a força útil que nos termos marxianos em nada se diferencia da força de um cavalo, mas captando também as aptidões cognitivas agora mobilizadas pela dinâmica dos jogos e dos prêmios.

Apesar disso, é preciso não superdimensionar essa função da PLR. TUMA, em estudo que analisa um amplo leque de acordos e convenções sobre o tema de 1994 à 1999, alerta que o empresariado brasileiro ainda não havia despertado para as funções mobilizadoras da PLR. Para a autora, o que prevalecera neste período analisado foi sobretudo a intenção de redução de custos devido ao caráter não remuneratório da parcela ${ }^{27}$. A intenção deste texto não é, portanto, enfatizar o modelo de participação com maior abrangência, mas sim apontar para novas formas de controle, mobilização e gestão da subjetividade que articulam-se com a normatização expressa em alguns acordos coletivos que tratam do tema. Trata-se não de uma pretensão de fidelidade estatística, mas sim de considerar um conjunto de novas formas de controle expressos em algumas pactuações coletivas. Pretende-

\footnotetext{
${ }^{25}$ Essa é a posição de MELLO e SILVA que, em estudo realizado em uma fábrica de cuecas no interior de São Paulo, demonstra como mesmo com todo um discurso pautado na noção de polivalência a qualificação ligada ao posto de trabalho não fora abolida. vide MELLO e SILVA, Leonardo. Trabalho em Grupo e Sociabilidade Privada. São Paulo: Ed. 34, 2004, p. 231- 258.

26 Os outros dois pontos já citados são: melhor adequação dos gastos com pessoal ao desempenho da empresa e uma redução de custos fixos.

27 TUMA, op. cit., p. 224-228. É óbvio que a análise de TUMA já encontra-se defasada na data atual, mas ela ao menos põe em dúvida uma visão que generalize o uso gerencial da PLR.
} 
se, portanto, mais exemplificar e apontar questões do que elaborar um quadro extenuante.

Optou-se, para tal empreitada, por analisar alguns acordos firmados no âmbito das indústrias do parque automobilístico da Região Metropolitana de Curitiba $(\mathrm{RMC})^{28}$. Trata-se de indústrias que incorporam em maior ou menor grau princípios de administração flexível como o trabalho em equipe, os Círculos de Qualidade Total, a valorização da polivalência, etc. Já no plano profissional estes acordos foram firmados pelo Sindicato dos Trabalhadores nas Indústrias Metalúrgicas, Mecânicas e de Material Elétrico de Grande Curitiba, geralmente em conjunto com uma comissão de empregados.

Em quadro elaborado pelo DIEESE ${ }^{29}$, em que consta a análise de acordos de Participação nos Resultados ${ }^{30}$ em cinco importantes empresas do ramo metalúrgico (New Roland, Comau do Brasil Ind. e Com. Ltda, Renault, Audi-Volks e Volvo ${ }^{31}$ ) desde 1998 à 2003, pode-se perceber que todas elas possuem sistemas de metas ligados à programas de qualidade - embora os nomes dados às mesmas possam ser os mais diversos (housekeeping, ISO 9002, Assegurança Qualidade Renault, etc.) - à produtividade e ao absenteísmo. O que difere é a articulação dessas metas, já que em alguns casos elas são aferidas pelo desempenho individual, de um coletivo restrito de trabalhadores (time de trabalho, área ou departamento) ou por todos os trabalhadores da empresa (excetuando-se os quadros de gerência).

As metas de absenteísmo encontradas nos acordos são todas individuais. As faltas ao trabalho, a partir de um determinado número, funcionam como redutoras do valor da participação a ser recebido individualmente. Neste caso, parece que se está diante não de um novo tipo de controle, mas da disciplina típica, com seus

\footnotetext{
${ }^{28}$ Para a compreensão da implantação da indústria automotiva no Paraná vide FIRKOWSKI, Olga L. C. de Freitas. Industrialização, questão ambiental e mercosul: breve análise da inserção do Paraná. In: R. RA'E GA, Curitiba, n. 2, p. 85-106. Ed. UFPR, ou ainda, MOTIM, Benilde M. Lenzi; FIRKOWSKI, Olga L. de Freitas, ARAÚJO, Sílvia Maria P., Desconcentração da indústria brasileira e seus efeitos sobre os trabalhadores a indústria automobilística no Paraná. Trabalho apresentado no IV Colóquio Internacional de Geocrítica. Barcelona 27, 28, 29 e 30 de maio de 2002.

29 Documento não publicado elaborado pelo DIEESE/CTBA (2004)

30 TUMA já havia apontado em seu trabalho uma preponderância da Participação nos Resultados. vide TUMA, op. cit., p. 202. O mesmo ocorre entre os metalúrgicos da RMC, sendo que não houve dentre os acordos analisados nenhuma incidência de participação nos Lucros.

${ }^{31}$ Além dos acordos presentes na pesquisa do DIEESE analizou-se também o acordo da FAURECIA BANCOS PARA AUTOMÓVEIS LTDA, fornecedora da RENAULT.
} 
métodos de ligar homens e mulheres ao aparelho produtivo através da pura e simples coação monetária. Caberia ainda perguntar-se por que, em nenhum dos acordos, a meta de absenteísmo aparece como uma meta coletiva? A resposta para tal questão demandaria um pesquisa das motivações do sindicato e da empresa ao negociar tal meta, mas apesar disso pode-se dizer que, ainda que sob uma forma disfarçada, o absenteísmo não é apenas uma questão individual. As metas que tratam de produtividade ou qualidade por equipe de certa forma já tornam pouco propício que estas se predisponham a ter entre os seus componentes operários que costumam não comparecer ao trabalho, o que faz com que mesmo que as metas de abstenção sejam individuais haja uma grande pressão para que os membros de uma determinada equipe não venham a faltar. Trata-se de uma coerção mútua, organizada pelos próprios trabalhadores ou pelo líder da equipe e que não precisa mais advir dos níveis hierárquicos superiores. A norma coletiva, neste caso, organiza uma espécie de vigilância recíproca que interiorizada transforma-se em autocontrole.

Já as metas por equipes ou times de trabalho, ligadas as metas de qualidade ou produtividade, por exemplo, guardam em si uma contradição interessante, que está no cerne dos novos sistemas produtivos. Ao mesmo tempo que valorizam a cooperação, o espírito de grupo e as qualidades comunicativas dos trabalhadores, contribuindo de certa forma para a superação da relação completamente individualizada que havia no fordismo puro entre o trabalhador e seu posto de trabalho, dá-se uma nova espécie de individualização. Neste caso, a dinâmica dos jogos é a tônica da disputa entre os grupos e até entre os próprios membros de cada equipe e a Participação nos Resultados a organiza. Ela legitima, através do próprio sindicato ou comissão que a pactua, que os times recebam a partir de metas e que com isso o desempenho de cada time possa ser periodicamente publicizado e os desempenhos comparados. A diferença passa a ser um instrumento de maximização dos esforços, já que nenhum dos times quer estar entre os menos produtivos. As possibilidades de organização coletiva dos trabalhadores são assim seriamente comprometidas. O coletivo de trabalhadores deixa de ser uma bloco homogêneo com interesses próprios, tornando-se um conjunto de microgrupos engajados em uma gincana infindável.

Esse aspecto lúdico, que a Participação nos Resultados contribui para organizar, possui um componente discursivo ligado principalmente a noção de 
endomarketing. Não basta que os consumidores tenham uma visão positiva da empresa, é preciso que os "colaboradores" vejam os seus interesses como indissociáveis dos da mesma, que estejam dispostos a aplicar todas as suas habilidades comunicativas e cognitivas a seu favor. Portanto, o primeiro ponto a ser dissolvido é a noção de conflito entre classes sociais antagônicas.

O esforço individual e coletivo deve ser premiado, e a Participação é um dos modos de fazê-lo. Mas a ela associam-se cartazes homenageando os trabalhadores ou times mais produtivos com as fotos dos respectivos "colaboradores", ou ainda, comemorações promovidas pela empresa no caso de atingimento de metas. Tudo de forma a valorizar o "capital humano".

Por fim, duas situações específicas podem ajudar a compreender as relações entre a Participação nos Resultados e novas formas de controle e gestão da subjetividade. Em primeiro lugar cabe ressaltar uma técnica presente na linha de produção da Audi-Volks, empresa automobilística situada em São José dos Pinhais. Trata-se de um placar presente em diversos pontos da linha de montagem que indica o número de carros que devem, de acordo com as metas, ser produzidos naquele dia e a estimativa de quantos serão efetivamente produzidos caso se mantenha a velocidade da produção daquele exato momento. Tem-se, portanto, as metas como um fator de tensão onipresente, alcançável ao olhar de todos, e que deve propulsionar uma constante adequação dos gestos, sempre no sentido da elevação da produtividade ao limite máximo ${ }^{32}$.

O segundo caso trata do acordo de Participação nos Resultados pactuado com a Faurecia Bancos para Automóveis. O interessante de tal acordo é que ele possui algumas diferenças importantes com relação aos demais analisados. Neste surgem duas novidades: as metas de produtividade são analisadas em nível individual e possui um sistema de metas denominado Eureka em que os trabalhadores devem, por ano, contribuir com 12 sugestões de melhorias sobre a qualidade ou produtividade do trabalho. Quanto ao primeiro aspecto parece apontar para um meio de desestabilizar aquilo que Castel denomina condição assalariada, ainda que partindo de seu interno. Tal condição baseia-se sobretudo em "um processo de desindividualização que insere o trabalhador em regimes gerais, 
convenções coletivas, regulações públicas do direito do trabalho e da proteção social"33. Mas o que é o pagamento por produtividade individual senão uma forma desestabilizadora da própria condição salarial e de suas formas de homogeneização e inscrição em uma coletividade? $O$ salário ${ }^{34}$ passa a ser uma experiência extremamente individual.

Já o segundo aspecto aponta para um nova dimensão da apropriação do trabalho vivo, ou seja, para uma apropriação não mais apenas dos mecanismos gestuais, mas da capacidade cognitiva do trabalhador, elevando o trabalho abstrato à um novo patamar em que a exploração caminha por mares antes não navegados.

\section{CONCLUSÃO}

Partindo-se do acordos firmados pelos Sindicatos dos Metalúrgicos de Curitiba pode-se perceber facilmente que a PLR vêm sendo utilizada em estreita associação com novas formas de gestão do trabalho ligadas ao que se pode chamar de reestruturação produtiva. Os acordos em sua totalidade apontam a inclusão de metas de qualidade e, em grande parte introduzem metas associadas aos times de trabalho, sendo que no caso mais extremo, percebido em um dos acordos (Faurecia) se dá a analise da produtividade de forma individual, através do cálculo da produção por jornada de trabalho.

As análises apontam que a introdução da PLR pode contribuir para uma maior individualização dos ganhos, que passa a depender cada vez mais do desempenho do trabalhador ou da equipe na qual ele se insere. Tal situação representa séria ameaça à construção de uma identidade coletiva dos trabalhadores autônoma em relação à empresa, já que o ambiente de trabalho passa a ser marcado por uma dinâmica de jogos em que todos são competidores entre si.

32 A observação de tais placas, que em muito lembram o sistema Andon da Toyota (sistema de semáforos que indicam o ritmo da linha), foi feita em visita a Audi-Volks, organizada pelo GETS (Grupo de Estudos de Trabalho e Sindicalismo)

${ }^{33}$ CASTEL, Robert. As metamorfoses na questão social: uma crônica do salário. 3 ed. Petrópolis: Vozes, 1998, p. 600.

${ }^{34}$ Esse referência não é juridicamente adequada já que a PLR é uma parcela não salarial, mas optouse, neste caso, por privilegiar um sentido comum de salário em detrimento de sua acepção técnica. 
Além disso, nestas circunstâncias, corre-se grande risco não só de que os trabalhadores passem a ser os próprios fiscalizadores dos companheiros de trabalho - já que a menor produtividade de uns pode representar o não atingimento das metas pela equipe - mas que passem a atuar de forma cada vez mais auto-punitiva através do que se pode denominar auto-controle. 